Кузнецова Е.В., д.э.н., профессор кафедры «Анализ хозяйственной деятельности и прогнозирование» РГЭУ «РИНХ», Ростов-на-Дону, Россия; kuev@mail.ru

Грушина В.А., студент 3 курса кафедры «Экономическая безопасность, учет и право» ДГТУ, Ростов-на-Дону, Россия; ivika459@gmail.com

РОЛЬ БУХГАЛТЕРСКОГО УЧЕТА В ОБЕСПЕЧЕНИИ ЭКОНОМИЧЕСКОЙ БЕЗОПАСНОСТИ

Аннотация. Статья посвящена роли бухгалтерского учета и его непосредственного влияния на экономическую безопасность предприятия. Ocобое внимание уделяется бухгалтерской деятельности, влияющей на экономическую защищенность компании.

Ключевые слова: бухгалтерский учет, управленческий учет, внутренний контроль, экономическая безопасность, рыночная экономика.

Kuznetsova E.V., doctor of Economic Sciences, professor " Analysis of economic activity and forecasting " RSEU, Rostov-on-Don, Russia;

kuev@mail.ru;

Grushina V.A, 3rd year student of the Department "Economic security, Accounting and law" DSTU, Rostov-on - don, Russia;

ivika459@gmail.com

\title{
THE ROLE OF ACCOUNTING IN THE ECONOMIC SECURITY
}

Annotation. The article is devoted to the role of accounting and its direct impact on the economic security of the enterprise. Particular attention is paid to accounting activities that affect the economic security of the company.

Keywords: accounting, management accounting, internal control, economic security, market economy.

Функционирование современного динамично развивающегося предприятия нельзя представить без четко действующего бухгалтерского учета. 
Согласно законодательству Российской Федерации, все организации, являющиеся юридическими лицами, обязаны вести бухгалтерский учет.

Бухгалтерский учет - сбор и накопление информации о финансовом положении организации на отчетную дату, а также финансовых результатах ее деятельности и движении денежных средств за отчетный период.[6]

Из данного определения можно сделать вывод, что бухгалтерский учет это один из важнейших регуляторов обеспечения экономической безопасности предприятия.

Основные определения понятий «Экономическая безопасность» сформулированные рядом авторов представлены в таблице 1 [3]

Таблица 1

\begin{tabular}{|c|c|}
\hline Автор & Содержание понятия \\
\hline Л. И. Абалкин & $\begin{array}{l}\text { Экономическая безопасность - это совокупность условий и } \\
\text { факторов, обеспечиваюших независимость национальной } \\
\text { экономики, ее стабильность и устойчивость, способность к } \\
\text { постоянному обновлению и совершенствованию }\end{array}$ \\
\hline В.К. Сенчагов & $\begin{array}{l}\text { Экономическая безопасность - состояние экономики и } \\
\text { институтов власти, при котором обеспечиваются } \\
\text { гарантированная зашита национальных интересов, } \\
\text { социальная направленность политики, достаточный } \\
\text { оборонный потенциал даже при неблагоприятных } \\
\text { условиях развития внутренних и внешних процессов. } \\
\text { Экономическая безопасносьь - это не только } \\
\text { зашищенность национальных интересов, но и готовность и } \\
\text { способность институтов власти создавать механизмы } \\
\text { реализации и защиты национальных интересов развития }\end{array}$ \\
\hline $\begin{array}{l}\text { Архипов, А. Городецкий, Б. } \\
\text { Михайлов }\end{array}$ & $\begin{array}{l}\text { Экономическая безопасность - это способность } \\
\text { экономики обеспечивать эффективное удовлетворение } \\
\text { общественных потребностей. }\end{array}$ \\
\hline С.Ю. Глазьев & $\begin{array}{l}\text { Безопасность экономическая - состояние экономики и } \\
\text { производительных сил общества с точки зрения } \\
\text { возможностей самостоятельного обеспечения устойчивого } \\
\text { социально-экономического развития }\end{array}$ \\
\hline Ю.С. Курочкин & $\begin{array}{l}\text { Экономическая безопасность - способность экономики } \\
\text { удовлетворять внутренний спрос и компенсировать } \\
\text { предложение (оплатить восполнение спроса) извне } \\
\text { собственными ресурсами }\end{array}$ \\
\hline
\end{tabular}

Для обеспечения экономической безопасности предприятия необходимо быстрое выявление и пресечение отрицательных эффектов в его деятельности. Так, с помощью качественной работы бухгалтерии можно обнаружить наличие или возникновение опасности для экономики предприятия.[1]

На предприятии может возникнуть такая ситуация, когда существует лицо или группа лиц, которые пытаются понизить качество работы 
бухгалтерии. В большинстве случаев только при неправильно ведущемся бухгалтерском учете можно реализовать получение личной выгоды сотрудниками за счет предприятия.

Список мероприятий проводимых для дестабилизации работы бухгалтерии:

1) неправильная организация документооборота;

2)отстранение бухгалтерии от ряда технологических процессов;

3)плохое материально-техническое обеспечение бухгалтерии;

4) навязывание бухгалтерии несвойственных ей функций;

5)препятствия нормальному функционированию бухгалтерии;

6) умышленные действия, направленные на подрыв авторитета главного бухгалтера и сотрудников бухгалтерии.

В качестве источника информации и способа управления бухгалтерский учет является одним из важнейших компонентов в обеспечении экономической безопасности. Благодаря бухгалтерскому учету все явления, которые происходят в деятельности предприятия, суммируются и контролируются.

После этого, на основе отдельных ведомостей, книг, журналов, таблиц, которые предназначены для регистрации хозяйственных операций, составляются обобщенные отчеты, предназначенные для надежной оценки экономического субъекта. Только с помощью этой информации предоставляется возможность оценить различные события и риски, которые оказали положительное или отрицательное влияние на компанию.

Ведение бухгалтерской отчетности не позволяет рискам превратиться в угрозы. Как известно, деятельность предприятий связана с разного рода рисками. Это происходит из-за того, что производственные условия попадают под влияние негативных факторов.

Риски приводят к отрицательным финансовым результатам предприятия в результате неправильного влияния на происходящие события. Положительным результатом можно считать правильную оценку и управление, приводящих к минимизации отрицательных последствий риска. 
Можно сделать вывод, что обеспечение экономической безопасности компании зависит от научного подхода к рискам, который и помогает уменьшить или ограничить негативные последствия.[2]

В условиях экономической системы, основанной на принципах свободного предпринимательства, а так же многообразие форм собственности, в бухгалтерском учете возникли новые проблемы, влияние которых отражаются на экономической безопасности организации. Эти проблемы связаны с такими факторами, как:

1)гибкость ведения бизнеса;

2)наличие рисков;

3)необходимость оценки рисков и их предотвращение;

4)устранение негативных последствий рисков;

5)повышение конкурентоспособности предприятия.

В современных условиях устанавливают новые виды управленческого и бухгалтерского учета, а также политики предприятия в целом. В рамках усовершенствования технологий и повышения конкурентоспособности появилась необходимость расширения числа объектов учета, для уменьшения и пресечения угроз, влияющих на экономическое состояние компании.[4]

Учетная политика должна приобрести формы и методы, которые непосредственно влияют на профилактику, надлежащую оценку и ограничение влияния угроз.

В таблице №2 представлены рекомендации, направленные на повышение роли бухгалтерского учета в обеспечении экономической безопасности хозяйствующих субъектов.[5] 
Таблица 2

\begin{tabular}{|c|c|}
\hline Проблема & Решение проблемы \\
\hline $\begin{array}{l}\text { Научное обоснование таких категорий, } \\
\text { как экономическая опасность, } \\
\text { экономическая безопасность } \\
\text { предприяти (компанин). }\end{array}$ & $\begin{array}{l}\text { Необходимо научно обосновать } \\
\text { концепции, такие как экономическая } \\
\text { опасность предприяпя, экономическая } \\
\text { безопасность, оценки и ограничения } \\
\text { экономической опасности предприятия. }\end{array}$ \\
\hline $\begin{array}{l}\text { Определение системы показателей, } \\
\text { характеризуюших опасность и } \\
\text { безопасность для суббьекта } \\
\text { предпринимательской деятельности. }\end{array}$ & $\begin{array}{l}\text { Разработать систему показателей, } \\
\text { характеризуюших экономическую } \\
\text { угрозу для безопасности бизнеса. }\end{array}$ \\
\hline $\begin{array}{l}\text { Разработка методов учета явлений, } \\
\text { которые обеспечивают экономическую } \\
\text { безопасность предпрпяти (компанин). }\end{array}$ & $\begin{array}{l}\text { Разработать методику учета } \\
\text { показателей, характеризуюших риск } \\
\text { экономической и безопасности } \\
\text { субъектов. }\end{array}$ \\
\hline $\begin{array}{l}\text { Oпределение методов и методик } \\
\text { бухгалтерского учета, предназначенньх } \\
\text { для отражения результата воздействня } \\
\text { экономической опасности на } \\
\text { безопасность бизнеса. }\end{array}$ & $\begin{array}{l}\text { Рекомендовать стандартную форму } \\
\text { учетной политикн экономических } \\
\text { агентов, которая отражает методы учета } \\
\text { и методы, которые предотврашают } \\
\text { возникновение экономической угрозы. }\end{array}$ \\
\hline $\begin{array}{l}\text { Предотвращение неблагоприяньх } \\
\text { последствий хозяйственной } \\
\text { деятельности предприятй должно стать } \\
\text { одной из важньг задач бухгалтерского } \\
\text { учета. }\end{array}$ & $\begin{array}{l}\text { Рекомендовать систему счетов в делях } \\
\text { содействия экономической безопасности } \\
\text { предприянй. }\end{array}$ \\
\hline
\end{tabular}

Таким образом, можно сделать вывод, что ключевым фактором, который определяет экономическую безопасность на предприятии, является бухгалтерский учет. Именно бухгалтерский учет определяет экономический статус хозяйствующего субъекта.

\section{СПИСОК ЛИТЕРАТУРЫ}

1. Экономическая безопасность. Учебно-методическое пособие/Крутиков В.К., - Калуга: ИП Стрельцов И.А. (Изд-во «Эйдос»), -2017. - 196 с

2. Экономическая безопасность предприятий. Подходы и принципы. Гапоненко В.Ф., Беспалько АЛ., Власков А.С.- М.: Издательство «Ось-89», 2007. - 208 c. 
3. Баранников, А.А., Сигидов, Ю.И. - Роль бухгалтерского учета и внутреннего контроля в обеспечении экономической безопасности организации / А.А. Баранников, Ю.И. Сигнидов. - Научный журнал КубГАУ.- 2012.

4. Толкачева, О.М., Толкачева, Н.А. Бухгалтерский учет и анализ: учеб. пособие для студентов всех форм обучения по направлению подготовки 080100.62 - Экономика / О.М. Толкачева, Н.А. Толкачева. - М.: Директ-Медиа, 2013. $-174 \mathrm{c}$.

5. Дворядкина, Е.Б. Экономическая безопасность: учеб. пособие/ Е., Дворядкина. - Екатеринбург: Изд-во Урал. гос. экон. ун-та, 2010. - 177 с.

6. Шумилина В. Е., Шевцова К. А., Мельникова О. С. Бухгалтерская отчетность как источник основных показателей экономической безопасности хозяйствующего субъекта // Актуальные вопросы обеспечения экономической безопасности в Российской Федерации в условиях цифровой экономики . AUS PUBLISHERS . 2018.2 C. $1-9 . \quad$ URL: https://auspublishers.com.au/ru/nauka/conference_article/2131/view (дата обращения: 17.10.2018).

\section{REFERENCES:}

1. Economic security. Textbook/Krutikov V. K., - Kaluga: IP Streltsov I. A. (Publishing house "Eidos"), -2017. - $196 \mathrm{~s}$

2. Economic security of enterprises. Approaches and principles. In The Dossier.F., Bezpalko AL. And Vlaskov.S.-M.: Publishing House "Axis-89", 2007. $208 \mathrm{p}$.

3. Barannikov, A. A., I. sigidov, I. the Role of accounting and internal control in ensuring the economic security of the organization / A. A. Barannikov, S. and Signalov. - The scientific journal of the Kuban state agrarian University.- 2012.

4. Tolkacheva, O. M., Tolkacheva, N. Ah. Accounting and analysis: studies. manual for students of all forms of training in the direction of 080100.62-Economics / O. M. Tolkacheva, N. Ah. Tolkacheva. - Moscow: Direct Media, 2013. - 174 p. 
5. Dvoryadkina, E. B. Economic security: textbook. allowance / E., Dvoryadkina. - Yekaterinburg: Publishing house Ural. state Econ. UN-TA 2010,. $177 \mathrm{p}$.

6. Shumilina V. E., Shevtsova K., Melnikova O. S. Accounting as a source of the main indicators of economic security of the economic entity .Actual questions of ensuring economic security in the Russian Federation in the conditions of digital economy. AUS PUBLISHERS . 2018. P. 1-9. URL: https://auspublishers.com.au/ru/nauka/conference_article/2131/view (date accessed: 17.10.2018). 